Recebido em 02/2019. Aceito para publicação em 04/2019.

\title{
TRANSGREDINDO AS LÓGICAS DE CUIDADO: RELATO DE EXPERIÊNCIA SOBRE O AMAR E BRINCAR NA PEDIATRIA HOSPITALAR
}

\section{TRANSGRESSING THE LOGICS OF CARE: REPORT OF EXPERIENCE ON LOVING AND PLAYING IN HOSPITAL PEDIATRICS}

Bruna Lima Selau ${ }^{1}$

Luiz Fernando Silva Bilibio²

Resumo: Este trabalho foi desenvolvido a partir da vivência de uma residente, em um hospital público, no cuidado de crianças vítimas de violência onde o amor e o brincar sempre integraram a composição do tratamento da saúde. O estudo tem como objetivo refletir sobre como o amar e o brincar inseridos na produção do cuidado hospitalar, podem favorecer a humanização desse atendimento às crianças vítimas de violência. As reflexões deste estudo foram construídas a partir do resgate da Política Nacional de Humanização e de aspectos etimológicos do termo humanização, das reflexões filosóficas propostas por Humberto Maturana em sua obra 'Amar e Brincar: Fundamentos esquecidos do Humano, e dos registros em diário de campo durante o percurso da pesquisa que será compartilhado por meio de um caso. Percebe-se, nesta trajetória, a potência, os desafios e os paradoxos existentes na inserção do amor e do brincar na produção do cuidado em saúde especialmente no contexto hospitalar.

Palavras-chave: Cuidado da criança; hospitalização; humanização da assistência; saúde coletiva; maustratos infantis.

Abstract: This work was developed based on my work as a resident student at a public hospital, taking care of the health of children who are victims of violence, where loving and playing have always been involved on the care. Thus, this study aims to reflect on how loving and playing during the hospital internment may help to produce a humanization of this care to children who are victims of violence. The reflections of this study were built from the National Humanization Policy and etymological aspects of the word "humanization", from the philosophical reflections proposed by Humberto Maturana in his "Loving and Playing: Forgotten Fundamentals of the Human" and the registers in my field diary, built during the research, that will be shared through a case. In conclusion, it was possible to identify the potentiality, the challenges and paradoxes existing in the insertion of loving and playing in health care production at a hospital organization.

Keywords: Childcare; hospitalization; humanization of care; public health; child abuse.

\section{INTRODUÇÂO}

De uma maneira geral, a produção do cuidado em ambiente hospitalar sempre acarreta desafios. Entretanto, talvez um desafio mais delicado e intenso seja aquele que ocorre em hospitais em que se tratam crianças vítimas de violência. Infelizmente, a violência acompanha a história e as transformações da humanidade e está presente nas diferentes esferas da vida social. Trata-se de um grave problema de saúde, constituindo-se entre as principais causas de morbimortalidade no mundo, sendo as crianças um dos alvos majoritários (AMARAL et al, 2013). Considerando que os casos

\footnotetext{
1 Mestranda em Saúde Coletiva na Universidade Federal de Santa Catarina - UFSC, Brasil. E-mail: blselau@gmail.com.

2 Doutor em Educação em Saúde. Docente da Escola de Educação Física, Fisioterapia e Dança, Universidade Federal do Rio Grande do Sul - UFRGS, Brasil. E-mail: fernando.bilibio@ufrgs.br.
} 
de violência infantil são um desafio contemporâneo, é preciso refletir sobre o cuidado proporcionado às crianças e aos adolescentes vítimas de violência no Sistema Único de Saúde (SUS).

O SUS foi idealizado tendo como princípios a universalidade, a equidade e a integralidade, a fim de proporcionar saúde para todos igualitariamente e com qualidade. Nesta perspectiva e além de outras dimensões, ganha relevância a dimensão emocional e de bem estar dos usuários dos serviços de saúde. Talvez estes aspectos sejam ainda mais estratégicos ao considerar o cuidado com crianças vítimas de violência na perspectiva da humanização.

O Programa Nacional de Humanização na Assistência Hospitalar (PNHAH) (BRASIL, 2001) e a Política Nacional de Humanização (PNH) (BRASIL, 2004) foram criados visando suprir as demandas que vão além da clínica tradicional, por meio da inserção do termo humanização do cuidado. Incorporam-se, assim, os ideais de solidariedade, respeito e dignidade ao processo de cuidar. Nesse sentido, é possível dizer que a criação e implantação do PNHAH e da $\mathrm{PNH}$ suscitam uma tensão entre, de um lado, os saberes e as práticas clínicas que - até então - não se ocupavam de maneira efetiva com valores como a solidariedade, o respeito e a dignidade no cuidado e, do outro lado, com os saberes e as práticas de saúde que não abrem mão de tais valores na sua composição.

Necessário refletir sobre o cuidado no nível terciário do sistema de saúde, uma vez que muitos casos de violência com crianças e adolescentes ainda chegam e somente são descobertos no próprio âmbito hospitalar. São situações que colocam em cheque a forte valorização da racionalidade tecnológica com ênfase nos equipamentos e conhecimentos especializados, em contrapartida a outras lógicas e sensibilidades ao cuidado. É nessa perspectiva que a humanização no ambiente hospitalar vem sendo mobilizada, visando um cuidado integral e generoso; pauta do cuidar como um ato solidário e fraterno.

Neste contexto, quando tratamos de cuidado humanizado a questão da qualidade da relação terapêutica ganha relevância. A dimensão do afeto como componente do cuidado ganha visibilidade nessa perspectiva, sendo que, no termo 'afetivo', encontra-se significação em termos como carinhoso, fraterno, amoroso, entre outros. Nesta direção, seria possível afirmar que trabalhar na perspectiva da humanização do cuidado com crianças implica em experimentar um tipo de relação também marcada por um dos sentimentos mais intrínsecos e próprios do humano: o amor. Caso seja este um dos desafios do cuidar da saúde de crianças, quais as implicações deste tipo de cuidado em ambientes hospitalares? Quais as potências produtoras de saúde neste tipo de abordagem? Quais os desafios de trabalhar em cuidado amoroso com crianças visando ganhos de saúde?

Em outro sentido, o brincar é uma estratégia de cuidado já bastante reconhecida como recurso terapêutico no cuidado da saúde de crianças que, além de uma forma 
de cuidar, faz parte da cultura infantil e é um direito das crianças. Dizendo de outra maneira, brincar faz parte do cuidado amoroso, humanizado com crianças e, assim, pensar o brincar torna-se uma estratégia de fortalecimento dos saberes e fazeres deste cuidado (AZEVEDO et al, 2007; MOTTA; ENUMO, 2004). Contudo, podemos significar o brincar em diferentes perspectivas. De um lado, o brincar pode ser visto como uma estratégia terapêutica para chegar a determinado objetivo de saúde. De outro lado, o brincar não apresentaria nenhum outro propósito para além do próprio desfrute do presente, do lazer. Uma tensão de saberes e práticas brincantes. Como habitar estes dois lugares no brincar? Trata-se da necessidade de definir exclusivamente o brincar como técnica, como estratégia que visa o futuro de saúde? Como seria considerar o brincar como desfrute do presente em ambientes hospitalares? Quais os riscos e desafios?

Reconhecendo as dores e as delícias de trabalhar com estes temas, o propósito deste artigo é produzir alguns sentidos sobre o amar e o brincar, quando inseridos na produção do cuidado hospitalar com crianças vítimas de violência. Para realizar essas reflexões, serão apresentadas algumas dimensões da Política Nacional de Humanização, resgatando aspectos etimológicos do termo humanização que permitem pensar o amar e o brincar na composição do cuidado em saúde. Na sequência do artigo, será compartilhado um caso (registrado em diário de campo durante o percurso da pesquisa), no qual o amar e o brincar estiveram presentes na produção do cuidado ocorrido durante o período da residente de educação física em saúde da criança em um hospital universitário da região sul do Brasil.

Por fim, a partir da obra 'Brincar e Amar: fundamentos esquecidos do humano do patriarcado à democracia' de Humberto Maturana e Gerda Verden-Zoller (2004), esse caso será revisitado com a intencionalidade de produzir alguns sentidos que possam contribuir para o debate sobre o amar-brincar como componente do cuidado amoroso e humanizado com crianças vítimas de violência e em ambiente hospitalar. Maturana e Verden-Zoller (2004) defendem que o amor e as emoções deveriam estar inseridos em nosso cotidiano, principalmente no âmbito do cuidar do outro. Deste modo, as produções destes pensadores representam perspectivas importantes e ainda pouco exploradas para indagar sentidos inerentes ao amar-brincar no contexto da saúde. Este artigo foi submetido e aprovado pelo Comitê de Ética do Hospital de Clínicas de Porto Alegre (HCPA), com número de projeto 15-0278.

\section{HUMANIZAÇÃO}

Para Fortes (2004), pensar a humanização em saúde implica compreender a singularidade dos indivíduos, respeitando seus valores, crenças, vivências e vontades, criando condições para manter a autonomia do usuário, evitando qualquer forma de discriminação negativa e, assim, preservando a dignidade do ser humano. Esta perspectiva da humanização em saúde tem seu fundamento na Declaração Universal 
dos Direitos Humanos (art. $1^{\circ}$ ), quando afirma que "todos os seres humanos nascem livres e iguais em dignidade e em direitos. Dotados de razão e de consciência, devem agir uns para com os outros em espírito de fraternidade" (UNESCO, 1998).

Nesta direção, no ano 2000, o Ministério da Saúde brasileiro (BRASIL, 2001) implementou o primeiro programa em prol da humanização ao atendimento em saúde: o Programa Nacional de Humanização na Assistência Hospitalar. Entre os seus objetivos está a difundir uma nova cultura de humanização na rede hospitalar pública brasileira e modernizar as relações de trabalho no âmbito dos hospitais públicos, tornando-os mais harmônicos e solidários, de modo a recuperar a imagem pública dessas instituições junto à comunidade (BRASIL, 2001). Trata-se da valorização da dimensão humana e subjetiva, presente em todo ato de assistência à saúde.

Em 2003, buscando a expansão do PNHAH para todos os níveis de saúde e na tentativa de expandir de modo transversal as concepções de humanização tanto para o atendimento quanto para a gestão, o Ministério da Saúde cria a Política Nacional de Humanização. Segundo esta política, a "humanização, como uma política transversal, supõe necessariamente que sejam ultrapassadas as fronteiras, muitas vezes rígidas, dos diferentes núcleos de saber/poder que se ocupam da produção da saúde" (BRASIL, 2004, p. 7).

Como política, a Humanização busca, portanto, traduzir princípios, valores e modos de operar no conjunto das relações entre profissionais e usuários, entre os diferentes profissionais, entre as diversas unidades e serviços de saúde e entre as instâncias que constituem o SUS. Segundo a PNH:

[...] o confronto de ideias, o planejamento, os mecanismos de decisão, as estratégias de implementação e de avaliação, mas principalmente o modo como tais processos se dão, devem confluir para a construção de trocas solidárias e comprometidas com a produção de saúde, tarefa primeira da qual não podemos nos furtar (BRASIL, 2004, p. 7).

Em relação à produção de sujeitos é possível perceber que as palavras solidariedade, respeito, ética, dignidade e harmonia estão consideravelmente presentes nos textos dessas políticas. Tratam-se de palavras caras às políticas de humanização. Deste modo, resgatar aspectos etimológicos de alguns destes termos parece configurar uma pertinente aposta de produção de sentidos entre a humanização do cuidado, o amar e o brincar.

Ao considerar o termo humanização, constata-se sua presença na história e em diferentes sociedades a partir das concepções de virtudes ligadas aos valores morais de amor fraterno, solidariedade e piedade. Esta concepção das virtudes ligadas à humanidade nasce no humanismo do Cristianismo primitivo a partir de suas fundamentações deísta e teológica com valores morais, piedosos e éticos ligados ao cristianismo primordial. Estes aspectos influenciam de maneira irreversível o conceito de Humanidade e as práticas de humanização construídas pela Reforma e 
Contrarreforma, iniciadas no século XIV (OLIVEIRA; COLLET; VIEIRA, 2006).

Entre os valores morais cristãos que têm ligação com a ideia de humanidade está a solidariedade. $\mathrm{Na}$ tradicional concepção cristã, a solidariedade tem uma profunda afinidade com a fraternidade que remete à noção de amor ao próximo todos são irmãos em Cristo. Assim, etimologicamente, é possível dizer que a ideia de amor ao próximo marcou a origem de distintas práticas sociais e políticas no ocidente, como a revolução francesa (fraternité) no final do século XVIII; processo social que irá influenciar a organização política dos Estados ocidentais até hoje.

Talvez seja possível dizer que a sociedade - pós revolução industrial do século XVII-IXX - vem tecendo uma rede de lutas em busca de políticas sociais de desenvolvimento do bem-estar comum, oriundas de valores de organização e compreensão social, na qual a solidariedade está historicamente entre seus principais fundamentos morais. Na América Latina, por exemplo, a Teologia da Libertação (1960) traz a ideia de solidariedade como estratégia de união dos "oprimidos" - chamados de sem dignidade e sem-direitos - para a luta contra determinada realidade social opressora (BILIBIO, 2009). A reforma sanitária brasileira também sofre influência dessas lutas políticas e sociais em busca de uma sociedade igualitária e com esses mesmos valores morais.

Assim, falar de saúde engloba esses valores e por isso as concepções de humanidade e de solidariedade também estão inseridas na construção dos princípios do SUS e em seus programas e suas políticas (BILIBIO, 2009); e guardando certa relação de sentido com atos de amor ao próximo. Dizendo com outras palavras, uma determinada ideia de amor faz parte do projeto doutrinário do SUS.

Nessa direção, o cuidado em saúde estaria ligado à polissêmica noção de amor na construção dos saberes e vivências com os usuários; uma ligação que legitima o próprio cuidado. Assim, na humanização da saúde, ganha legitimidade a contaminação amorosa das práticas de saúde, e o brincar pode ser considerado uma dessas práticas.

A trajetória da recreação terapêutica em ambientes hospitalares ganha relevância na perspectiva das políticas de humanização. Na recreação terapêutica e no brincar, todos podem ser atores, tanto os usuários quanto os profissionais de saúde. As regras, os jogos, as atividades seriam construídas em harmoniosas parcerias e modificadas de acordo com os participantes. Dessa maneira, o brincar seria uma ferramenta para resgatar o humano do cuidado em saúde, tendo em vista suas potencias de lazer, de prazer e de reconhecimento do outro como sujeito único e igual em dignidade.

Essa construção mútua dos cuidados em saúde transgride a lógica de produção pautada pelo paradigma racionalista problema-solução, que parece caracterizar o cuidado hospitalar. De certa maneira, a implantação da humanização implica o 
tensionamento de hegemônicas formas de produção exercidas pelos profissionais de saúde inseridos em ambientes hospitalares - desestabilizar os saberes dos núcleos profissionais e a lógica instrumental das práticas de saúde (BILIBIO, 2009). Dizendo de outro modo, a aposta da humanização é construir uma relação com o usuário composta de trocas ao invés de imposições. Assim, a partir da construção dessa relação horizontal com o usuário, os profissionais de saúde tornar-se-iam suscetíveis à inclusão dos sentimentos e das emoções no modo de operar as técnicas de saúde; o amar e o brincar entrariam na agenda da saúde, desestabilizando a própria produção da saúde.

O caso que segue trata desta agenda desestabilizada; trata de acontecimentos amar-brincar que ocorreram durante o percurso de residente, mais especificamente, na área de concentração em saúde da criança. Tais acontecimentos são agora compartilhados, visando à produção de sentidos, mirando questões sobre o amarbrincar que ainda demandam aprofundamentos. Um compartilhamento que busca ser elemento para a compreensão posterior daquilo que foi experimentação de cuidado em ato (MERHY, 2002) durante a relação de cuidado com Chaves.

\section{E AGORA QUEM PODERÁ ME DEFENDER?}

A primeira vez que vi Chaves ele estava sentado em um carrinho de bebê; ele tinha oito anos de idade. Sozinho e sem nenhuma expressão no rosto. Ele tinha oito, mas não aparentava mais de três anos de vida. Alguém da enfermagem o havia levado para a sala de recreação do hospital e colocaram-no olhando um desenho na televisão. Era um menino muito magrinho, pequeno e parecia ser muito frágil. Estava todo sujo, provavelmente acordou e nem tiveram tempo de lavar seu rosto. Fiquei observando aquela criança que não interagia com o meio, sem acompanhante, virada para a televisão, não demonstrando nem alegria e nem tristeza: nada!

Sentei ao lado de Chaves e tentei me comunicar. Não obtive sucesso. Peguei uma bolinha pequena e colorida de plástico e dei para ele brincar. Ele ficou segurandoa, me olhou e atirou a bola no chão. Mas, voltou a me olhar. Peguei a bolinha e devolvi para ele. Ficamos fazendo isto durante um tempo. Continuei brincando. Tirei-o do carrinho de bebê. Chaves jogava a bolinha e se locomovia arrastando-se sentado. Pegava a bola e ia me mostrar. Assim começou nossa interação. Nossa relação começou num jogo de bola; num tipo de vai e vem!

Quando conheci Chaves, ele havia recém internado; voltou após uma semana em casa. Antes já havia ficado no hospital de forma contínua em torno de oito meses. A residente anterior, que era a responsável por ele e que havia lhe ensinado muitas coisas, me falou um pouco sobre sua história e como construiu o vínculo entre eles. No início, então, brincávamos nós três, pois ele sentia muita confiança nela e aos poucos ele começou a confiar também em mim. 
Fiquei tão apegada a Chaves e a nossa relação estabelecida em nosso brincar, que pedi para ser a responsável, entre os profissionais de educação física, pela atuação na equipe que Ihe assistia. Ouvi a sua história; algo que me deixou muito mobilizada. O abandono já marcava a vida de Chaves. Ele havia sido internado com um risco muito grande de morte e aparentando sinais de negligência. Chaves foi adotado por um casal e era esta mãe adotiva sua principal cuidadora. Contudo, ela faleceu assim que o menino foi internado no hospital pela primeira vez, e a partir daí quem ficou responsável por cuidá-lo foi o pai adotivo. O pai pouco sabia sobre seus cuidados e suas singularidades, não havia um vínculo estabelecido entre eles. Além disso, o pai também estava muito doente, então pouco aparecia no hospital.

Comecei a brincar e interagir como se ele tivesse mais ou menos um ano de idade, visto que ele estava conhecendo tudo, pois sabia muito pouco. Brincávamos juntos. Durante o brincar eu era voluntariamente invadida pela sensação do presente. Vivenciávamos juntos o presente. Uma vivência na qual sentia o compromisso ético (e técnico?!) de dar afeto e atenção de forma lúdica. Parecia que, diante da difícil história que ele viveu, era o que mais precisava; pelo menos era assim que eu sentia. Era um menino com muito medo do novo e de interagir com outras pessoas e crianças; desconfiava de tudo que era proposto e tinha dificuldades de se vincular às pessoas.

Além de brincar, eu senti que precisava ensiná-lo, pois, sentia que havia muitas coisas que ele precisava aprender, e como Chaves era uma criança com dificuldade interagir por apresentar comportamentos prévios de desamparo e solidão, eu assumi essa tarefa. À medida que criamos um vinculo muito forte, comecei a ser uma referencia para ele e ser a referencia dele para o resto da equipe. Falar em mim era falar nele e falar nele era falar em mim. A cada problema que tinham com ele vinham me chamar. Ensinei-o a engatinhar, a caminhar, a comer, a escovar os dentes e até para a hora do banho eu era chamada, pois ele tinha medo. Assim, todos os problemas que a equipe encontrava com manejo da criança, eu era chamada. Se ele não se "comportava", eu tinha que ir conversar com ele e as enfermeiras ameaçavam: 'Olha que eu vou chamar a Bruna'!

Tudo o que ensinei foi em relação de afeto e com brincadeiras; acho que acontecia um tipo de amor! Entretanto, tudo foi bem mais complicado, porque aprender para alguns é uma brincadeira, mas para ele era sempre um desafio. A cada nova proposta ele chorava, e o que era para ser um aprendizado divertido acabava deixando de ser. Algumas vezes a atividade era desgastante. Isso gerava sofrimento nele... e em mim.

Continuei brincando com o Chaves e nosso vínculo se tornava mais forte. Eu amava passar aquele tempo com ele, e ele também ansiava por passar o tempo comigo. Então comecei a me perguntar: qual era o papel que eu estava exercendo na vida dessa criança? Ao mesmo tempo em que o Chaves se apegava a mim, eu me apegava a ele. Meu trabalho era com uma criança que tinha seus próprios 
sentimentos, e eu como um ser humano também tenho os meus - seria possível que nossos vínculos ultrapassassem as barreiras do relacionamento terapêutico e do trabalho no ambiente hospitalar? Perguntava-me se deveria ter deixado envolver-me por esses sentimentos.

Estava diante de uma situação complicada: assistir a uma criança que não tinha uma família para cuidá-la ou uma casa para morar. Muitas vezes me deparava pensando se não teria sido melhor só ter trabalhado tecnicamente ao invés de construir laços emocionais. Seria possível separar o saber técnico do viver emocional quando se trata deste tipo de trabalho? Naquele momento me parecia impossível.

Apesar de todas as dúvidas, mantive a relação com aquela qualidade afetiva. No vínculo e no afeto, cada vez mais fortes, seu medo excessivo foi diminuindo; amorosamente construímos uma relação de cuidado. Essa relação nos ajudou muito a vencer os medos; estive ao lado dele em várias de suas conquistas. Ele começou a aceitar novas propostas e demonstrar afeto em relação às pessoas: agora brincávamos de abraçar, fazer cócegas. Além disso, mostrava sentimentos e emoções diante das situações, sorria quando estava feliz e também brigava quando não queria algo.

Já fazia quase um ano que o Chaves estava nessa segunda internação. Diante desse cuidado, carinho, ternura e amor que encontrou ali, a recreação e o hospital tornaram-se o local onde ele se sentia em casa. Quando ele chegou ao hospital não brincava e não conseguia interagir com as pessoas, mas agora além de interagir com todos, ele sorria, ele amava. Aos poucos se aproximava a hora dele ir embora do hospital. Hora de ser acolhido institucionalmente. Mas isso já é outra história...

\section{SOCIEDADE E CUIDADO A PARTIR DE MATURANA E VERDEN-ZOLLER}

Quais os sentimentos mobilizados por essa história? Como os sujeitos estão envolvidos? Como acontece esse brincar? O que está certo ou errado nesse cuidado? Como esse cuidado atravessa o contexto hospitalar? A produção de sentidos sobre estas questões tem como referência o livro 'Amar e Brincar: fundamentos esquecidos do humano, do patriarcado à democracia', escrito em 2004 por Humberto Maturana, juntamente com Gerda Verden-Zoller, Neste contexto, são relevantes as formulações desenvolvidas por Maturana e Verden-Zoller (2004) em relação à sociedade.

Segundo esses autores, conserva-se um legado da cultura patriarcal europeia em nossa cultura ocidental moderna. Esta cultura seria centrada na dominação sobre o outro e a natureza, bem como no controle das condutas e das emoções. Construiuse, assim, relações de autoridade e subordinação, vivendo como se todos os atos requeressem o uso da força e como se cada ocasião para agir fosse um desafio a fim

de controlar o futuro. A cultura patriarcal valoriza a guerra, a competição, a luta, as hierarquias, a autoridade, o poder, a apropriação de recursos e a justificação racional 
do controle e da dominação dos outros por meio da apropriação da verdade, não tolerando o diferente (MATURANA;VERDEN-ZOLLER, 2004). Muito da produção tecnocientífica configuraria estratégias de dominação.

Ainda, esses autores Maturana e Verden-Zoller (2004) enfatizam que o amor e a solidariedade - por serem considerados um tipo de fraqueza - poderiam trazer prejuízos aos fins estabelecidos. Buscar-se-ia a dominação do outro nas escolas e nos serviços de saúde, principalmente quando adultos tecnicamente capacitados, apropriam-se de uma suposta verdade e cultivando-a como legítima.

No âmbito da educação básica, ao invés de educar para o amor, solidariedade, inclusão do diferente, somos responsáveis por habilitar as crianças a neutralizar as emoções em prol de um saber reto, lógico, duro (RESTREPO, 2000). Esse modo de educar permanece (e talvez se intensifique) na formação acadêmica, resultando em profissionais da saúde frutos do vivenciar de tal processo educativo de nível superior. Essa assertiva encontra essonância em Restrepo (2000, p. 15): "o que resta, no final de um período de formação acadêmica, não é só um conjunto de conhecimentos, mas também, e de maneira muito especial, um conjunto de hábitos, de escrúpulos morais e comportamentos rotineiros". Para este autor, esta composição profissional acaba "exercendo um grande poder de regulamentação cognitiva sobre o educando". Esse modo de pensar (nossa cultura) e o como se aprende a atuar profissionalmente (a educação) leva a um pensamento lógico e reto, refratário aos sentimentos mundanos; aos sentimentos que emergem na vida (BILIBIO, 2013).

Contudo, para Maturana e Verden-Zoller (2004) existe outra referência cultural: a matrística. Esta cultura matrística estaria efetivada nos tempos em que os seres humanos viviam em harmonia com o outro e com a natureza. Esta cultura valoriza a emoção, o amor e respeito ao próximo e à natureza, a solidariedade, a tolerância, a inclusão, a colaboração e a divisão. Uma compreensão e uma atitude que ainda perpetuariam na existência do ser humano (mesmo de maneira contra-hegemônica em alguns espaços), na busca por uma sociedade democrática e igualitária, por exemplo, nos movimentos em defesa dos direitos humanos, na reforma sanitária e nos próprios princípios do SUS.

Para Maturana e Verden-Zoller (2004) a cultura matrística, apesar de não ser vivida de maneira mais efetiva na atual sociedade, teria deixado um legado dentro da própria cultura patriarcal. Na construção de ideais (e práticas) de solidariedade e fraternidade e em experiências infantis também se estaria vivendo elementos da cultura matrística. Apesar de na vida adulta preservar-se a visão patriarcal, quando criança se estaria propenso a vivências matrísticas, ou seja, um viver centrado na apreciação do presente e na construção de relações baseadas no amor. $\mathrm{Na}$ perspectiva matrística é esperado na infância um viver centrado no amor, na despreocupação com o tempo e com as responsabilidades.

A perspectiva matrística de Maturana e Verden-Zoller (2004) permite suspeitar 
que e estaria diante da possibilidade de outros tipos de compromissos com a saúde construídos com ideais matrísticos e que, talvez, possam ser traduzidos em cuidado humanizado. Um cuidado também composto pelo amar-brincar nos relacionamentos e nos atos de saúde.

\section{O BRINCAR COMO DIMENSÃO DE CUIDADO}

Encontrar um significado para o ato de brincar não é tarefa fácil; principalmente quando se esquece de como foi vivida a infância. Maturana e Verden-zoller (2004) pensam o brincar a partir da cultura matrística - cultura que influência o viver na infância - pautada no amor e no viver o presente. Segundo os autores, o brincar e suas interações não teriam nenhum objetivo, nem visariam ao futuro. Esta perspectiva do brincar estaria ligada a um brincar matrístico. O brincar matrístico seria qualquer atividade vivida no presente e desempenhada de modo emocional, ou seja, não apresentaria nenhum propósito que fosse exterior à própria atividade. Não há uma preocupação com o objetivo do brincar, ou com as consequências desse brincar. Brinca-se quando se está atento ao que se faz, gostando do que se faz, no momento em que se faz.

Pode-se entender o brincar como um recurso, ou seja, uma atividade executada pela criança (ou pelos adultos que utilizam brincadeiras com crianças), visando ao futuro ou a fim de superar algum trauma do passado. Nesta perspectiva é empregada uma visão utilitarista ao ato de brincar, designando ao brincar, objetivos e fins. Esta compreensão do brincar está ligada ao modo de pensar da cultura patriarcal. Aqui, as emoções vividas pela criança, durante a brincadeira, são desvalorizadas em favor da razão atribuída pelos adultos; um tipo de brincar patriarcal. A recreação hospitalar parece ocorrer hegemonicamente nesta direção.

No cuidado hospitalar, o brincar deve ser estabelecido a fim de obter resultados futuros de saúde, dessa maneira se utilizaria o brincar em sua visão patriarcal. Quando se utiliza o brincar como instrumento terapêutico, a brincadeira pode ser empregada, por exemplo, visando o enfrentamento das tensões provocadas pelo próprio contexto do hospital e/ou na preparação para experiências dos processos invasivos de saúde. Assim, o brincar é recurso tecno-instrumental de auxílio ao profissional de saúde.

$\mathrm{Na}$ perspectiva deste trabalho, considerar a relação entre brincar e as práticas hospitalares é constatar que se está diante de dois modos de saberes e práticas do brincar: a matrística e o patriarcal. Nas vivências como residente em saúde, na história de cuidado com Chaves, parecem eclodir esta tensão de saberes e práticas brincantes. Como o ambiente hospitalar, historicamente, está centrado na lógica patriarcal, a inserção da recreação hospitalar também estaria predisposta ao brincar patriarcal. Assim, como profissionais atuantes deste processo, se é estimulado para a 
prática de um brincar que traga benefícios para o tratamento da criança; algo totalmente pertinente a uma instituição de saúde. Deste modo, muitas vezes no trabalho com Chaves, foi vivenciado o brincar em sua forma patriarcal; visando a uma futura melhora em seu desenvolvimento motor. Assim, ao realizar essas brincadeiras o intuito era alcançar processualmente, pelo relacionamento terapêutico, uma futura e possível melhora, visando um à alta hospitalar do menino.

Por outro lado, grande parte dos momentos com Chaves, pelo menos aqueles mais vivos na lembrança, foram invadidos por outra atmosfera brincante: brincar em seu modo matrístico. Por exemplo, o primeiro momento de interação foi guiado fortemente pelo simples ato de brincar. A vontade de ocorrer algo agradável e prazeroso entre residente e menino hospitalizado. Não houve fixação na busca do seu desenvolvimento motor! Naquela brincadeira não importava o futuro, mas sim, o presente do brincar, da interação, do prazer que aquelas brincadeiras proporcionavam aos dois. A relação terapêutica do cuidado acabou sendo construída muito por momentos como esses.

A vivência como residente foi habitar esses dois lugares no brincar; e suas tensões de saberes. De um lado, o brincar patriarcal, que se origina do saber que se adquiriu durante a formação acadêmica - das tradicionais referências biomédicas que configuram o paradigma problema-solução - no qual o brincar é só uma técnica para promover, proteger e recuperar a saúde das crianças. De outro lado, o brincar matrístico, pautado na brincadeira em atitude amorosa/solidária com o outro, no qual os profissionais e as crianças se permitem brincar de forma atuante, onde cada um se torna produtor do seu brincar e dos seus significados, dividindo, nessa relação, suas angústias e seus momentos de alegria.

Diante dessas duas perspectivas do brincar, e considerando o contexto de vulnerabilidade na qual essas crianças estão inseridas, seria pertinente ao cuidado definir exclusivamente o brincar como uma técnica? Como estratégia ao futuro saudável? Saggese e Maciel (1996), propõem que, no ambiente hospitalar, o brincar seja utilizado apenas como instrumento terapêutico a serviço da intervenção médica, e não como forma de recreação, porque assim se visaria apenas a ocupação de tempo ocioso. Nesta lógica, o brincar teria uma aplicação exclusivamente técnica, a fim de auxiliar nos procedimentos médicos e tendendo a alcançar as normas de saúde arbitradas pelas referências biomédicas. Nesta linha, não se estaria supervalorizando o modo de saber e brincar patriarcal e desvalorizando os outros saberes e significados do brincar?

O brincar em sua lógica patriarcal está inserido na literatura, e existem muitos trabalhos que abordam suas contribuições terapêuticas: como enfrentar com segurança a ansiedade provocada pela situação de hospitalização, melhor aceitação de procedimentos e exames, maior colaboração com a equipe de saúde, imagem mais positiva da hospitalização e recuperação pós-operatória mais acelerada (AZEVEDO et 
al, 2007; MOTTA; ENUMO, 2004). Esta assertiva leva ao contínuo considerar o brincar apenas como um meio para produzir benefícios à saúde; como uma técnica a serviço da intervenção médica e desconsiderando os outros aspectos psicossociais dessa atividade. Qual a possibilidade de inclusão do brincar matrístico neste cenário? Como suportar um brincar descompromissado com o futuro em ambientes hospitalares?

No brincar matrístico não há busca por um objetivo fazendo com que a atividade aconteça de maneira fluída e não de maneira programada. Assim, a cada brincadeira se estaria diante de um encontro horizontal, entre as pessoas envolvidas na experimentação da alegria. Estar aberto a este tipo de encontro poderia deixar a relação tu-eu suscetível a vivências que modificariam seus modos de ser e agir diante um do outro. Nessa relação prazerosa que acontece durante o brincar, o outro seria reconhecido como um legítimo outro em coexistência (MATURANA; VERDENZOLLER, 2004), logo o brincar aconteceria em atitude amorosa.

O que se percebe na relação de cuidado com Chaves e a partir da leitura de Maturana e Verden-Zoller (2004) é que existe uma vivência insubstituível, legítima e amorosa quando se assume profundamente o brincar matriarcal. No entanto, tal vivência no ambiente institucional da saúde, é atravessada, tensionada, recebe intervenções do brincar patriarcal. Ou ainda, o brincar previsto no hospital costuma ser o patriarcal, mas imprevistos amorosos e brincantes podem acontecer; e até deveriam.

\section{O AMAR COMO DIMENSÃO DE CUIDADO}

Falar de amor em nesta sociedade patriarcal não é simples; principalmente no contexto do trabalho em saúde onde muitas emoções e a sensibilidade parecem ter sido excluídas das rotinas produtivas. "O amor e o êxito econômico e social parecem andar na contramão" (RESTREPO, 2000, p. 23). Para Maturana e Vender-Zoller (2004), o amor é a emoção central na história evolutiva do ser humano. Este sentimento fundamenta o social e é definido como "disposição corporal sob a qual uma pessoa realiza as ações que constituem o outro como um legítimo outro em coexistência" (MATURANA; VERDEN-ZOLLER, 2004, p. 235).

Desse modo, apenas quando se é reconhecido e amado é que se consegue construir a identidade e respeito próprios. Nessa perspectiva, quando há a negação do amor na infância, ocorre uma profunda violação da construção da identidade da criança; negação de seu ser. Para cuidar do outro a fim de reconhecê-lo como sujeito integrante da sociedade em que vive, esse cuidado deveria acontecer com base no amor, em um cuidar fraterno e solidário. Um cuidar na filosofia matrística!

O amor torna-se, a partir dessa concepção, um importante componente no cuidado de crianças vítimas de violência. Desse modo, se inseriria também, o cuidado matrístico no cuidado em saúde. Em um artigo escrito por Hecht e Silva (2009), relatam que bebês que tinham seus cuidados biológicos atendidos, mas que quase 
não recebiam um cuidado amoroso apresentavam dificuldades no seu desenvolvimento e, aos poucos, iam perdendo interesse por se relacionar; o que na, maioria das vezes, os levava ao óbito.

Nessa mesma perspectiva, Sousa (2006) problematiza o cuidado de crianças vítimas de violência e afirma a necessidade de um cuidado com qualificação afetiva e solidariedade; seria um tipo de cuidado matrístico? Em seu artigo a autora relata que:

"A gestão do cuidado veste-se da ética da qualificação afetiva como substrato para suas ações. [...] É uma gestão que se pensa ao pensar o que faz para o outro, que não aparta a dimensão emocional da razão que constitui nossa capacidade de reflexão, que não afasta 0 sentir do pensar e os vivencia como integração corpórea complexa de nossa humanidade" (SOUSA, 2006, p.19).

Entende-se que foi vivenciado um cuidar matrístico na experiência relatada com o menino Chaves; estabelecendo-se o vínculo e a recíproca relação de carinho. Acredita-se que foi por meio da construção de uma relação de carinho e confiança que Chaves conseguiu construir uma vida afetiva e social, sendo possível perceber sua alegria em viver de novo. É possível encontrar estudos indicando a potência desta qualidade na produção de saúde (AMARAL et al, 2007; HECHT; SILVA, 2009; MATURANA; VERDEN-ZOLLER, 2004; SOUSA, 2006). Entretanto, ainda é preciso refletir sobre os desafios para os profissionais de saúde e implicações desse cuidado no contexto hospitalar.

O cuidado solidário e amoroso implicaria o sentir junto com outro. Uma coexistência na qual aquilo que acontece a ele não seria indiferente a mim, marcada por uma relação empática. Por exemplo, a dor de uma criança violentada transformase na dor daqueles que são seus agentes cuidadores (SOUSA, 2006). Como profissionais de saúde e agentes desse cuidado há necessidade de se estar capacitado e habilitado para este tipo de demanda, mas será possível preparar-se para esses sentimentos, para essa relação? Que tipo de preparação seria esta?

Nessa compreensão, esta residente permitiu-se ser afetada por sentimentos, pela relação e pela criança, e se tornou passível de sentir-se empática, ou seja, sentir o que o outro sente, sofrer com seu sofrimento, sorrir com suas alegrias, vivenciando um processo de um sentimento de compromisso, de implicação com o outro, avançando além das suas demandas biológicas. Porém, ao assumir esse cuidado matrístico no contexto hospitalar, talvez se fosse considerado profissional frágil ao demonstrar um cuidado amoroso ao outro. Mas realmente seria frágil aquele profissional de saúde que assume o cuidado além da dita dimensão técnica, que se envolve em um cuidado amoroso e se aventura em sorrir e sofrer com o outro? Seguir a lógica patriarcal e trabalhar apenas no estreito corredor tecnocientífico (não se afetando com o outro) seriam características de um profissional da saúde melhor e mais forte? Para tanto, é preciso, lançar mão de da outras cognições teóricas e práticas que fundamentam a relação terapêutica que costuma ser vivenciada por outros profissionais de saúde de forma multi e interprofissional. 


\section{CONSIDERAÇÕES FINAIS}

A relação com Chaves foi cheia de alegrias e tristezas, prazeres e desprazeres, gostosuras e procedimentos, brincadeiras e aprendizados, ou seja, um jogo de tensões de saberes e práticas, de razões e sentimentos. Foi vivenciar diferentes modos de cuidar e brincar, e estar diante de tensões com o tradicional modo de ver o processo saúde-doença no ambiente hospitalar.

As concepções de saúde, baseadas nas tradicionais referências biomédicas que configuram o paradigma problema-solução e a educação, fundamentada na técnica, configuram os profissionais de saúde, impulsionando-os a um brincar-cuidar patriarcal. São esses saberes e práticas biomédicas que legitimaram o modo de pensar saúde, em aliança ao projeto moderno-científico-capitalista de regulamentação da vida social, instigando um conhecimento significativamente forte e que modula a memória profissional nos diferentes núcleos de trabalho na saúde, até hoje (BILIBIO, 2013). Entretanto, o trabalho em saúde pode torná-los suscetíveis e invadidos pelos prazeres do cuidar do outro; do brincar no presente. Ao mesmo tempo, também leva aos processos espinhosos de um cuidado solidário; do sofrer com o outro. Assim, o amar-brincar matrísticos provoca e faz lembrar que o trabalho na saúde envolve seres humanos cuidando de outros seres humanos, e que o cuidar não está baseado só em técnicas e protocolos, mas sim, em ver o outro além de seus aspectos biológicos e vivenciar a respectiva vertigem dos seus aspectos psico, sócioespirituais.

Deste modo, trabalhar com o amar-brincar dentro do ambiente hospitalar é estar diante de uma tensão de saberes e práticas. Continua sendo um desafio desconstruir saberes patriarcais estruturados e amar-brincar dentro do ambiente de saúde. Logo, escolher trabalhar com o amar-brincar matrístico neste contexto é estar disposto a vivenciar uma tensão da escolha por uma atitude de cuidado que - na lógica patriarcal - parece ser entendida como desnecessária e inapropriada.

É importante ressaltar que na vivência desta outra forma de cuidar, não se está negligenciando possíveis e futuros ganhos de saúde, não se trata de negá-los, contudo, a visualização de tais ganhos, a antevisão de um melhor estado de saúde não dominaria o ato de amar e brincar. A atenção dos envolvidos estaria intensamente envolvida no próprio brincar. Na brincadeira matriarcal em hospital, a atenção do cuidador está hegemonicamente tomada pela fruição do brincar. Todavia, uma residual parte da atenção provavelmente estaria comprometida à terapêutica. Ou seja, tratarse-ia de uma fina sintonia na qual a potência do encontro alegre e amoroso ganharia relevância, provocando um dinâmico intercâmbio no foco de atenção do trabalhador de saúde que aceita o desafio das influências matrísticas.

Em outro sentido, provavelmente, os possíveis e desejados ganhos de saúde seriam constatados mais significativamente somente após esses momentos, depois das vivências brincantes. A devida leitura da situação (e alteração) de saúde viria depois do brincar; tempo em que a atenção estaria mais disponível para estas 
necessárias análises do cuidado. Dizendo de outro modo, num brincar também matrístico, ocorreria, durante o brincar, uma racionalização amorosa no atendimento às necessidades terapêuticas, retomando-a na evolução e avaliação do cuidado.

Portanto, amar-brincar é reconhecer o outro como um legítimo ser em coexistência. É proporcionar um cuidado afetivo que nos convoca a ir além das lógicas binárias de causa e efeito, enquadradas em prescrições daquilo que conforma 0 dever-ser de cada profissional, ou seja, viver seu papel técnico e afetivo ou expressivo na assistência ao ser humano sob seu cuidado. É estar aberto a uma relação de cuidado que se faz e se refaz na convivência, que reconhece em todas as atitudes o cuidado como dimensão fundante do amor. Entretanto é preciso reconhecer que viver - lado matrístico, vivenciar o amar-brincar no cuidado dessas crianças dentro das instituições de saúde, é estar disposto a viver conflitos e desafios diários os quais, muitas vezes, desvaloriza a lógica patriarcal hegemônica, o desafio de ainda estar à margem do instituído. Estariam os profissionais de saúde e as instituições dispostos a aplicar seus conhecimentos, suas habilidades e atitudes técnicas e afetivas recebidas em suas formações para esse modo de cuidar e pensar saúde?

\section{REFERÊNCIAS}

AMARAL, L. V. O. Q. et al. Significado do cuidado às crianças vítimas de violência na ótica dos profissionais de saúde. Revista Gaúcha de Enfermagem, v. 34, n. 4, p. 146152, 2013.

AZEVEDO, D. M. de et al. O brincar como instrumento terapêutico na visão da equipe de saúde. Ciênc. cuid. saúde, v. 6, n. 3, p. 335-341, 2007.

BILIBIO, L. F. S. Por uma alma dos serviços de saúde para além do bem e do mal: implicações micropolíticas à formação em saúde. 2009. Dissertação (Doutorado em Educação) - Universidade Federal do Rio Grande do Sul, Porto Alegre, 2009.

BILIBIO, L. F. S. Esquecimento Ativo e práticas corporais em saúde. In: Alex Branco Fraga; Yara Maria de Carvalho; Ivan Marcelo Gomes. (Org.). As práticas corporais no campo da saúde. São Paulo, v. 01, p. 117-138, 2013.

BRASIL. Ministério da Saúde. Secretaria de Assistência à Saúde. Programa Nacional de Humanização da Assistência Hospitalar. Brasília: Ministério da Saúde. 2001.

BRASIL. Ministério da Saúde. Secretaria de Atenção à Saúde. Núcleo Técnico da Política Nacional de Humanização. Humaniza/SÚS: documento base para gestores e trabalhadores do SUS. 4. ed. Brasília: Ministério da Saúde, 2004.

FORTES, P. A. C. Ética, direitos dos usuários e políticas de humanização da atenção à saúde. Saúde e Sociedade, v. 13, n. 3, p. 30-35, 2004.

HECHT, B.; SILVA, R. Crianças institucionalizadas: A construção psíquica a partir da privação do vínculo materno. 2009. 20f. Trabalho de Conclusão de Curso (Graduação em Psicologia) - Pontifícia Universidade Católica do Rio Grande do Sul, Porto Alegre, 2009.

MATURANA, H. R.; VERDEN-ZOLLER, G. Amar e brincar: fundamentos esquecidos 
do humano do patriarcado à democracia. São Paulo: Palas Athena, 2004.

MERHY, Emerson Elias. Saúde: a cartografia do trabalho vivo. Hucitec, 2002.

MOTTA, A. B.; ENUMO, S. R. F. Brincar no hospital: estratégia de enfrentamento da hospitalização infantil. Psicologia em estudo, v. 9, n. 1, p. 19-28, 2004.

OLIVEIRA, B. R. G.; COLLET, N.; VIEIRA, C.S. A humanização na assistência à saúde. Rev Latino-am Enfermagem, v.14, n.2, p. 277-284, 2006.

RESTREPO, L. C. O direito à ternura. 2. ed. Petrópolis: Vozes, 2000.

SAGGESE, E. S. R.; MACIEL, M. O brincar na Enfermaria Pediátrica: recreação ou instrumento terapêutico. Pediatria moderna, v. 32, n. 3, p. 290-292, 1996.

SOUSA, Ana Maria Borges de. O sentido institucional de acolher: por uma gestão do cuidado com as crianças. In: SOUSA, Ana Maria B.; VIEIRA, Alexandre; LIMA, Patrícia de Moraes. Ética e Gestão do Cuidado: a infância em contextos de violências. Florianópolis: CED/UFSC/Núcleo Vida e Cuidado-NUP, 2006.

UNESCO. Declaração Universal dos Diretios Humanos. Brasília, 1998. Disponível em: <https://unesdoc.unesco.org/ark:/48223/pf0000139423> Acesso em: 14 mar. 2019. 